\title{
Study and Practice on the Talent Training System of Applied Physics Specialty
}

\author{
Yaxiang Bai ${ }^{\star a}$, Yucai $\mathrm{Hu}^{\mathrm{b}}$ and Jing $\mathrm{Wang}^{\mathrm{c}}$ \\ School of Science, Dalian Ocean University, Dalian, Liaoning Province, China \\ a1450917123@qq.com, bhyc@dlou.edu.cn, cwangj@dlou.edu.cn
}

Keywords: Applied physics specialty; Talent training system; Teaching content; Creative and practical ability; Theoretical teaching system; Practical teaching system

\begin{abstract}
In order to further improve the teaching quality of applied physics specialty in Dalian Ocean University and cultivate students' creative and practical ability, we formed the training system that reflects school characteristics, highlights interdisciplinarity and adapts to social needs, established the curriculum system constituted by theoretical teaching system, practical teaching system, quality and innovation education system and obtained good results.
\end{abstract}

\section{Introduction}

The talent training system reform has been a concerned issue in higher education teaching reform, as well as the core of educational and teaching reform [1-3]. In recent years, the higher education in our school has developed into mass education from elite education. Our school actively meets the social demands and proposes to put the cultivation of students' practical ability and innovative application ability on an important position. According to the general requirements of school talent training mode reform, based on the discipline construction need and social talent demand, the applied physics specialty in our school made continuous exploration and reform for the specialty talent training system in order to improve the personnel training quality and enhance the employment ability of graduates. The specific measures are as follows:

Optimize the training program, build a more reasonable curriculum system and strengthen the practical teaching.

\section{Optimize the specialty training program to embody the school characteristics and highlight the interdisciplinarity}

Dalian Ocean University is a multidisciplinary university that sets up agriculture, industry, science, management, literature and other disciplines with ocean, aquaculture, fisheries, biology, environment and other subjects as the characteristics. The engineering course covers machinery, electronics, construction, information, food engineering and other subjects. From the discipline structure features and subject characteristics in our school, the reasonable allocation of school teaching resources and the promotion of the interdisciplinarity between ocean, biology and environmental engineering subjects and the applied physics, are the outstanding advantages. Therefore, in modifying the training program, we consider the combination of science and technology, the penetration of agriculture and engineering. In addition to physics course, we also opened electrical technology, electrotechnics, engineering drawing and other engineering courses and constructed the knowledge structure combined with science and technology; we used the strong ocean, biology and environment basis of our school and regarded marine biology, environmental biophysics, environmental monitoring and other courses as feature courses, so as to highlight the school characteristics. Through the cross-curriculum arrangement, students can not only be familiar with the macro thinking characteristics, but also grasp the microcosmic research method, so as to meet the social demand for applied physics talents in different aspects. 


\section{Strengthen the training of the computer application ability in order to meet social requirements}

The computer technology is an indispensable tool in modern production and life. The application of $\mathrm{C}$ programming language and computer in physics, Matlab curriculum design, computer programming language, $\mathrm{CAD}$ and creative design, and other courses highlight the application of computer technology and regard the computer practice as an important way of the course learning for the research of specific physical problems. By this way, students can not only implement the modern scientific technology and method, but also know the treatments of specific physical problems. In recent years, for the great demand for IT industry talents and the development demand of some IT enterprises in receiving physics students, we timely adjusted the professional training program and increased JAVA program design, computational physics, JAVA curriculum design, application system development and other IT courses while maintaining the original biological and physical characteristics. These course have greatly broadened students' employment channels and their ability in the IT field.

\section{In order to improve the ability of students to adapt to different jobs, update the professional curriculum system}

The curriculum system is the carrier of talent training objectives and training mode, the direct embodiment of educational thought and ideology, as well as a decisive factor restricting the teaching quality [4-5]. Therefore, according to the training objectives, we constructed reasonable curriculum system and teaching contents through careful research and discussion. Our general ideas is: "guarantee the foundation, widen the aperture, face demands, highlight application and reflect the characteristics". The constructed curriculum system are consisted of three parts, theoretical teaching system, practical teaching system and innovative teaching system. The characteristic of the theoretical teaching system is hierarchy and it realizes the system optimization. According to the knowledge level, three knowledge platforms are constructed, namely public basic and general courses, basic courses, specialized courses and professional centralized practice, innovation and entrepreneurship educational courses. The public basic and general courses mainly include series of quality education courses.

Meanwhile, the demand of current enterprises for the higher applied talents that master basic theoretical knowledge and have high practical ability. For the change, we strengthened the reform and innovation efforts of the talent training mode and cultivated the applied talents that can be retained and applied that enterprises need. For the changing situation of the demand for the the knowledge structure of applied physics of different fields of the current society, we further expanded students' knowledge field through opening the general elective courses and directional elective courses and expand the employment channels of graduates. Then, students can choose the directional and practical technical courses better according to their own interests. For example, we opened optoelectronic technology, development and application of modern physics, applied acoustics, nanotechnology and functional materials, computer network application, the application of simulation technology in engineering and other courses with strong applicability. Thus, students can choose different courses according to their own interests and the working fields that they plan to be engaged in.

Try to connect the undergraduate education and postgraduate education in order to explore the approach to achieve the win-win of undergraduate education and postgraduate education

The undergraduate-postgraduate successive training mode is a training mode with the whole consideration of undergraduate stage and postgraduate stage. According to characteristics of our specialty, the biomedical engineering and biophysics, we developed the basic undergraduate-postgraduate successive mode and method for the students majored in applied physics, biomedical engineering and biophysics. The specific measures are: select several outstanding students majored in applied physics every year, carry out the tutorial system during the three years in college, do scientific research training and graduation thesis in advance; the postgraduate students who are directly admitted by the biomedical engineering and biophysics majors in our school continue their studies under the guidance of the tutor. They can finish a master's degree within two years, 1 year earlier than other 
graduate students. Meanwhile, the applied physics students can also attend some biomedical engineering and biophysics graduate courses in the form of elective courses. If the students that take these courses as elective courses are admitted to the biomedical engineering and biophysics colleges for postgraduate study, they can no only re-study these courses, but directly get the corresponding credits. It will not only improve the undergraduate teaching quality, but also solve the small number and low quality problems of the biomedical engineering and biophysics students.

\section{Strengthen the practical teaching in order to improve the students' innovative and entrepreneurial ability}

The practical teaching is an important part of the applied physics course [6]. Learning physics knowledge is not enough to learn physics well. The classroom teaching enable students to master the basic knowledge and basic skills of physics and meet the basic discipline requirements. And students' interest and potential are mainly developed and mined through extracurricular practice. Therefore, the extra-curricular scientific and technological practice activity has become an important mean for college students to give full play to potential, form innovation consciousness, cultivate innovation ability and accumulate innovation experience, as well as a main means to cultivate students' practical ability [7]. In order to do a good job in students' extra-curricular scientific and technological practice activities, we carried out a reform. First of all, strengthen publicity and education, so as to make students know the importance of extracurricular scientific activities, the participation means and ways as soon as possible. Thus, when students just entered the school, we gave lectures about the extracurricular scientific knowledge, extracurricular entrepreneurship contest and other extracurricular scientific activity knowledge, which can make students establish a correct learning concept and mobilize their enthusiasm in participating in extra-curricular scientific activities. Secondly, for the actual situation that college students have more free time than middle school students, complete the organization and guidance of extracurricular activities, teach through lively activities, call on and support students to participate in all kinds of scientific innovation, entrepreneurship and research projects, so that they can direct experience the innovative and entrepreneurial process. Then, encourage students to take the advantage of holidays to practice, feel and look for opportunities, strengthen students' understanding of the society and strengthen their social adaptive ability. Thirdly, use all available research resources, such as the oceanophysics laboratory in Liaoning, and make students personally contact test instrument, thus developing their practical ability and scientific innovation ability; fourthly, expand the number of the students who participate in extra-curricular scientific activities, improve the quality of activities, encourage students to establish interest groups in a certain direction and prompt them to grape the basic knowledge required by the scientific research activities; fifthly, actively guide students to participate in various scientific and technological competitions, such as Challenge Cup Extracurricular Science Contest, Challenge Cup Extracurricular Entrepreneurship Competition, Liaoning Physics Experiment Competition, Liaoning Physics Academic Competition, etc., and foster their innovative consciousness. In this way, the students' innovative consciousness, practical ability and scientific innovation ability can be gradually developed.

\section{The effects can be achieved}

Through the reform and innovation for several years, the training of students majored in applied physics has achieved good results. In recent years, the employment situation of students is increasingly better. The employment surface is broader and broader and the employers involve physics, marine, electronics, electrical appliances, IT, biology, environment and other fields. After entering these companies, students can quickly adapt to the job and most of them have good performance. Through the feedback information of employers, on the whole, the training quality and professional quality evaluation results are good. For example, Dalian Modern High-tech Development Co., Ltd., Dalian Huanyue Technology Development Co., Ltd. and other companies expressed that the applied physics graduates have good comprehensive quality and strong adaptive ability. They generally reflected that the applied physics 
graduates work hard and can finish various tasks timely with quality and quantity assured. With strong initiative, they can undertake the assigned tasks. With strong learning ability and working ability, they always take advice modestly, study hard and apply themselves to the work within a short time. With strong team spirit, they are able to get along well with the leaders and colleagues. They never care about personal gains and losses, as well as the workload. They are willing to bear the burden of hard work. Besides, they have solid professional knowledge and certain innovative consciousness..

\section{Acknowledgements}

This research was financially supported by the Dalian Ocean University.

\section{References}

[1] X.N. Fu, K. Liu: Journal of Zhengzhou Institute of Aeronautical Industry Management ( Social Science Edition), Vol. 28 ( 2009) N0.4, 134-136. (In Chinese)

[2] L. X. Zhou, D.S. Wang and F.D. Men: Higher Education of Sciences, Vol. 95 (2011) N0.1, 78-81. (In Chinese)

[3] L. Li, C.G. Ma:Science and Technology Innovation Herald, (2005) N0.18, 144. (In Chinese)

[4] Y. W. Luo, X.N. Fu: Journal of Zhengzhou Institute of Aeronautical Industry Management ( Social Science Edition), Vol. 28(2009) N0.5, 160-162. (In Chinese)

[5] B. Wang, J.P. Zhang: IERI Procedia, Vol. 2 (2012), 414-419. (In Chinese)

[6] F.W. Zhang: Journal of Zhengzhou Institute of Education, Vol. 33 (2013), N0.5, 60-61. (In Chinese)

[7] J. Wang, M. Yao and J. Chen: Laboratory Science, 7(2009) N0.1, 69-71. (In Chinese) 